\title{
PAISAGEM, LUGAR E PATRIMÔNIO NATURAL SOB A ÓTICA SISTÊMICA: OS CALDEIRÕES DE LAJEDO (PE)
}

\author{
Jeovanes Lisboa da Silva Filho ${ }^{(a)}$ Leticia Florentino Dias de Oliveira $^{(b)}$ Maria Betânia \\ Moreira Amador ${ }^{(c)}$ \\ (a) Graduando em Geografia (UPE), Campus Garanhuns. E-mail: jeovanelisboa@ @otmail.com \\ (b) Graduanda em Geografia (UPE), Campus Garanhuns. E-mail: leticia.idias@bol.com.br \\ (c) Professora Doutora em Geografia da (UPE), Campus Garanhuns. E-mail: betaniaamador@ yahoo.com.br
}

\section{Eixo: GEODIVERSIDADE, GEOARQUEOLOGIA E PATRIMÔNIO NATURAL}

\begin{abstract}
Resumo
$\mathrm{O}$ presente trabalho traz à tona os Caldeirões na cidade de Lajedo (PE), enquanto patrimonio natural do lugar. O objetivo foi realçar a questão "patrimonal natural" dos Caldeirões por meio da percepção que se tem desta área. A pesquisa é de natureza qualitativa onde, além da revisão bibliográfica teve-se a técnica da observação para identificação de problemas ambientais e registros fotográficos. Identificou-se impactos ambientias nos Caldeirões em si, mas também na paisagem como um todo, além da falta de apreço e compreensão da importância deste lugar para a história e cultura. Espera-se que haja mundanças de percepção e, em consequencia, valorização desse lugar que, inclusive, remete ao nome do municipio.
\end{abstract}

Palavras chave: Lugar, Paisagem, Patrimônio Natural, Topofilia, Sistemismo.

\section{Introdução}

No interior de Pernambuco, existem áreas com valores culturais patrimoniais, tanto de cunho geológico-geomorfológica, quanto de flora, fauna, recursos hídricos entre tantos outros elementos naturais que acabam por dar importância e significado ao lugar, seja por seu aspecto visual paisagístico, ou seja por sua relevância histórica cultural já registrada, e até mesmo os valores intangíveis que pode, inclusive, contribuir para o turismo local.

Quando nos remetemos a Amador (2015), verifica-se que nas terras nordestinas, especificamente no Agreste de Pernambuco, encontram-se diversas paisagens geológico-geomorfológicas, algumas delas ricas em elementos arqueológicos, outras ricas em minerais, cuja exploração econômica é possível e viável. Outras se sobressaem pela sua beleza, funcionalidade entre outros valores com potencial para, eventualmente, promover a visitação turística e, em consequência, o desenvolvimento econômico local. 
XVII Simpósio Brasileiro

de Geografia Fisica Aplicada

I Congresso Nacional de Geografia Física
OS DESAFIOS DA GEOGRAFIA FÍSICA NA FRONTEIRA DO CONHECIMENTO

Instituto de Geociências - Unicamp

Campinas - SP

28 de Junho à 02 de Julho de 2017

Neste trabalho de iniciação cientifica traz-se à tona uma área natural da cidade de Lajedo (PE), denominada de Caldeirões. São rochas de diversas formas e profundidades, as quais acumulam água em suas cavidades e que, também, carregam consigo um significado histórico, cultural, social e ambiental para o município de Lajedo e região Agreste de Pernambuco, o que dá mais coesão e robustez ao seu valor patrimonial de caráter natural.

Quanto a metodologia utilizada, optou-se pela abordagem sistêmica, por compreender a sua eficiência em conseguir visualizar e concatenar a complexidade inerente no âmbito de estudos ambientais. Para tanto, Suertegaray (2005), enfatiza que devemos recorrer ao sistemismo na Geografia, não como uma teoria apenas interpretativa, mas um caminho analítico, um método. Recorreu-se também, ao levantamento bibliográfico associado ao uso das técnicas de observação para identificação de alguns problemas ambientais, e fotografias embasando, assim, as considerações aqui traçadas.

\section{2. Área de estudo}

O município de Lajedo (figura 01), está geograficamente localizado na Mesorregião do Agreste de Pernambuco e na Microrregião de Garanhuns (PE), e apresenta uma altitude de aproximadamente 661 metros. Seu clima varia do sub úmido ao semiárido, por estar inserido numa área de transição entre a zona fisiografica do Sertão e a Zona da Mata, ou seja, o Agreste. De acordo com a estimativa do Instituto Brasileiro de Geografia e Estatística (IBGE, 2016), a população lajedense é de aproximadamente 39.570 habitantes.

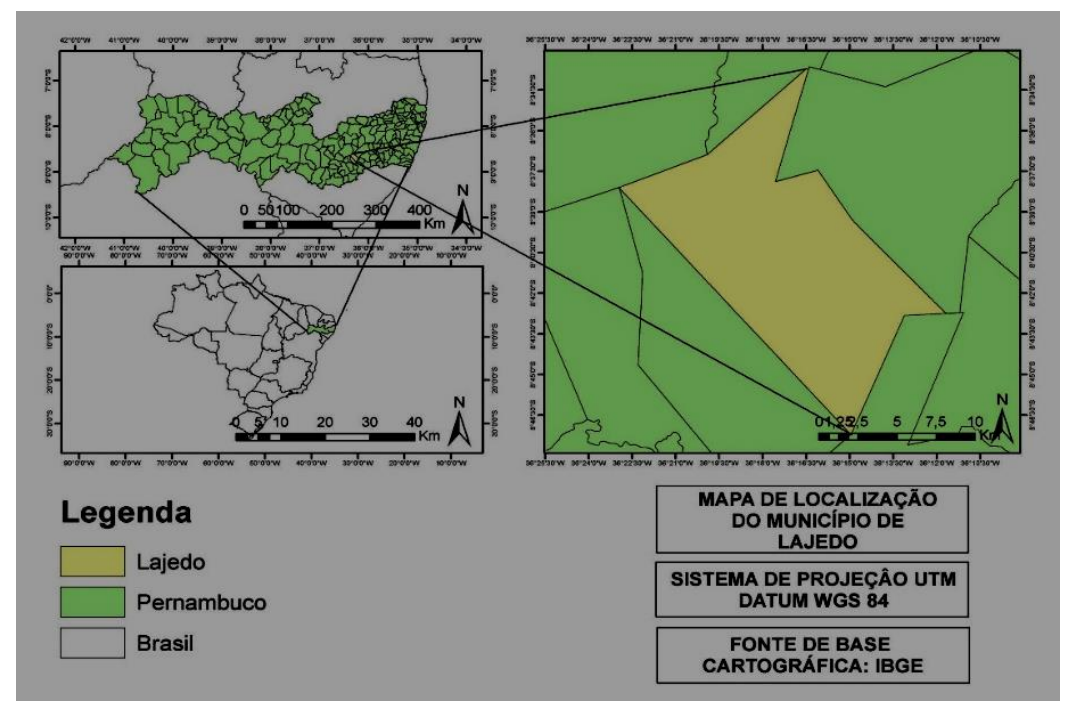

Figura 01 - Localização do Município de Lajedo (PE). Adaptado por Renilson Ramos (2015) 
Os Caldeirões (figura 02), foram os elementos primeiros em grau de importância para o processo de ocupação do lugar onde foi edificada a cidade, como também foram fundamentais no abastecimento de água para as mais diversas utilidades, tais como: lavar roupa, tomar banho, pescar, fazer piquenique, cozinhar, entre outras utilidades para as famílias que residiam nas proximidades.

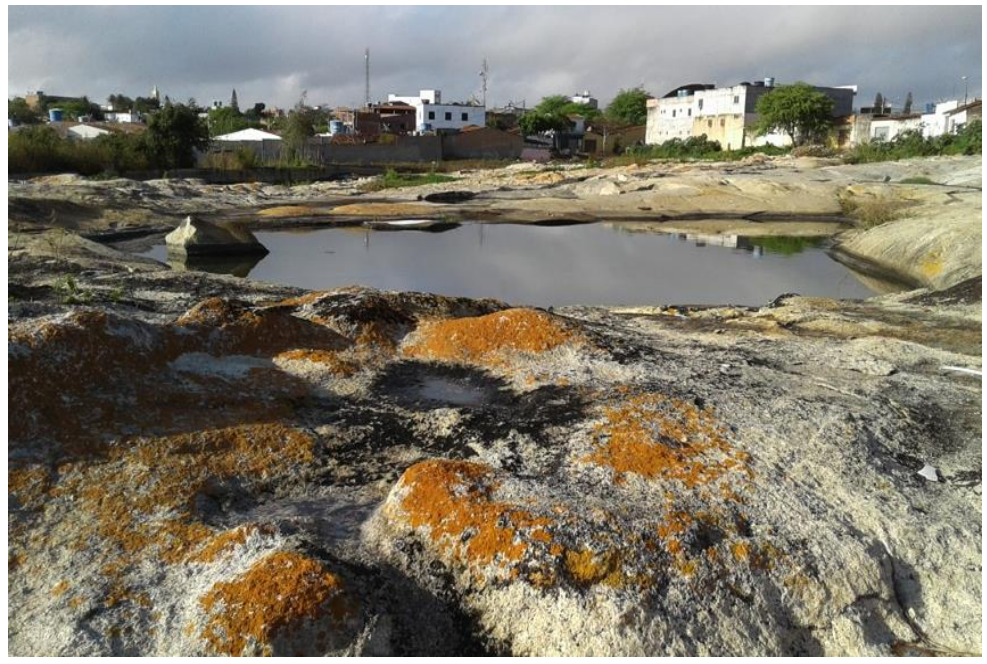

Figura 02 - Vista parcial dos Caldeirões em Lajedo (PE). Fonte: Arquivo de J. Lisboa (2016)

Devido à todas as suas utilidades já elencadas, além da importância histórica, cultural, patrimonial, os Caldeirões localizados na área central da cidade, acabaram sendo catalogados pelo Plano de Preservação dos Sítios Históricos do Interior (PPSHI), desde 1982 e o Plano Diretor Municipal (2003), os classificam como área de proteção ambiental (APA), a fim de assegurar a sua preservação e conservação e, ainda, em seu artigo 12, os incisos I e III, destaca que para a organização e produção do espaço urbano serão adotadas as seguintes diretrizes:

1. Respeito a geomorfologia do sítio natural, sobretudo no que se refere à topografia, lençol freático, e qualidade do solo; no processo de ocupação e expansão da área urbana;

3. Proteção das áreas e do patrimônio de relevante valor cultural e natural, assegurando a preservação de suas peculiaridades locais.

Os respectivos incisos remetem aos Caldeirões enquanto patrimônio natural e cultural de Lajedo (PE), cabendo então evidenciar a ideia de preservação desse patrimônio, diga-se cultural, histórico, geomorfológico entre outros.

\section{Fundamentos Teóricos}

Neste trabalho, toma-se como categoria de análise do espaço geográfico, o lugar. Assim, inicialmente temos como referência o Yi Fu Tuan, o qual em sua obra "Topofilia": valores e 
atitudes ao meio ambiente, expressou como se pensar e agir no lugar com afetividade. Nesse contexto, "entende-se que Topofilia é:

Um neologismo, útil quando pode ser definida em sentido amplo, incluindo todos os laços afetivos dos seres humanos com o meio ambiente material. Estes diferem profundamente em intensidade, sutileza e modo de expressão. A resposta ao meio ambiente pode ser basicamente estética: em seguida, pode variar do efêmero, prazer que se tem de uma vista, até a sensação de beleza, igualmente fugaz, mas muito mais intensa, que é subitamente revelada (...) são os sentimentos que temos para com um lugar, por ser o lar, o locus de reminiscências e o meio de se ganhar a vida. (TUAN, 2012, p. 107).

Ainda, dentro da ótica conceitual, trazemos à tona o conceito de paisagem, uma vez que o presente trabalho realça o "lugar e paisagem" de maneira integrada e indissociável. De acordo com Cavalcanti (2014), ele afirma que:

As paisagens acumulam a história de processos tectônicos, geomorfológicos, climáticos, hidrológicos e culturais, mas são, antes de tudo, entidades de ordem do presente, pois constituem o resultado geoecológico e visível da interação de elementos e processos naturais e culturais. (CAVALCANTI, 2014, p. 19).

Importa, ainda, ressaltar a proeminência do sistema, uma vez que a perspectiva da pesquisa tem como prioridade utilizar a abordagem sistêmica em seu caminho metodológico. Dentro da ótica conceitual de sistema traz-se à tona o Bertalanffy $(2015$, p. 63), que define sistema como sendo "um conjunto de elementos em interação". Já um outro autor, o Morin, concebe sistema como sendo "uma unidade global organizada de inter-relações entre elementos, ações ou indivíduos" Morin (2003) apud Amador (2011, p. 87). Já em relação à abordagem sistêmica, e/ou sistemismo, Amador (2006), chama atenção para a seguinte afirmação:

Pensar e agir sistemicamente, em qualquer área de estudo, requer refletir problemas sob o aspecto da ordem, da organização, da totalidade, entre outros. Logo, são abordagens que fogem ao tradicional reducionismo da ciência que, busca entender os fenômenos, prioritariamente, pelo observável e pelo testável, fundamentado sobremaneira na física e na matemática, vindo a contribuir ao longo do tempo na extrema especialidade que esquece, ou não encontra espaço para entender o todo, ficando retido, apenas, na questão da causa e efeito de forma linear. (AMADOR, 2006 p. 26).

E, com relação ao patrimônio natural, (MARTINI, 1994 apud PEREIRA, 2006), enfatiza que se refere aquele não construído, e que é a base de todas as formas de vida, e do homem em particular que, pela sua complexidade, dinâmica e sensibilidade, representa as sociedades humanas. Muitos outros autores poderiam serem aqui realçados mas, a nível de reflexões introdutórias, os aqui supramencionados são suficientes para o pretendido.

\section{Considerações Finais}


Mesmo sabendo-se de todas as potencialidades que os Caldeirões têm para Lajedo e região Agreste de Pernambuco, no tempo presente, esse patrimônio encontra-se esquecido e abandonado pela maioria da população. Verificou-se também uma série de impactos ambientais dos Caldeirões em si, e na paisagem, o que induz a pensar na necessidade tanto da sustentabilidade, quanto de se pensar em formas de valorização da paisagem geomorfológica do lugar que possa ser subsidiado, talvez, por um trabalho de educação ambiental voltado, sobretudo, para as crianças locais.

\section{REFERÊNCIAS}

AMADOR, Maria Betânia Moreira (Org.) Sistemismo e sustentabilidade: questão interdisciplinar. São Paulo: Scortecci, 2011.

AMADOR, Maria Betânia Moreira. "Topofilia" aplicado ao estudo de componentes geomorfológicos considerados patrimônios no Agreste de Pernambuco. Revista Equador. V 04, no 03, ano 2015. Edição especial 02. p. 171-177, 2015.

BERTALANFFY, Ludwig von. Teoria geral dos sistemas: fundamentos, desenvolvimento e aplicações. 10 ed. Tradução de Francisco M. Guimarães. Petrópolis, Rio de Janeiro: Vozes, 2015.

CAVALCANTI, Lucas Costa de Souza (Org.) Cartografia de paisagens: fundamentos. São Paulo: Oficina de Textos, 2014.

IBGE. Instituto Brasileiro de Geografia e Estatística. 2016 Disponível em: <http://www.cidades.ibge.gov.br/xtras/perfil.php?lang=\&codmun=260880\&search=pernambuco|lajedo $>$. Acessado em Janeiro de 2016.

MARTINI G. (1994): Bilan général de la protection du patrimoine géologique en France. Memoires de la Societé Géologique de France, 165, 111-118.

MORIN, Edgar. Introdução ao pensamento complexo. Tradução de Eliane Lisboa. Porto Alegre: Sulina, 2015.

Plano Diretor do Munícipio de Lajedo. Lei 1.112. /2003. LAJEDO (PE).

SILVA, Vanderly Marinho da; BASTOS, Sênia Regina. Valorização da formação geológica Caldeirões como patrimônio e atrativo turístico de Lajedo, Pernambuco. Anais do Conic-Semesp. v. 1, 2013, pp. 0110.

SILVA FILHO, Jeovanes Lisboa; AMADOR, Maria Betânia Moreira. Os Caldeirões de Lajedo/PE no Contexto de sua Paisagem Geomorfológica. In: Periódico Eletrônico do XI Fórum Ambiental da Alta Paulista. Biodiversidade e Unidades de Conservação. v. 11, n 01, 2015, pp 16-31.

SUERTEGARAY, Dirce Maria Antunes. O atual e as tendências do ensino e da pesquisa em geografia no Brasil: Revista do Departamento de Geografia, n. 16, p. 38 - 45, 2005.

TUAN, Yi-Fu. Topofilia: um estudo da percepção, atitudes e valores do meio ambiente. Tradução de Lívia de Oliveira. São Paulo: DIFEL, 2012. 